\title{
Desmistificando os estudos de tendências
}

\author{
Demystifying trend studies
}

Resenha de: MONÇORES, Aline (org.). Tendências: mitos, métodos e experiências sobre consumo e futuros. Barueri: Estação das Letras e Cores, 2020.

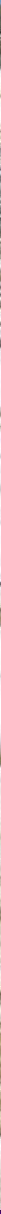


Márcia Mesquita ${ }^{1}$

ORCID: https://orcid.org/0000-0002-7910-9791

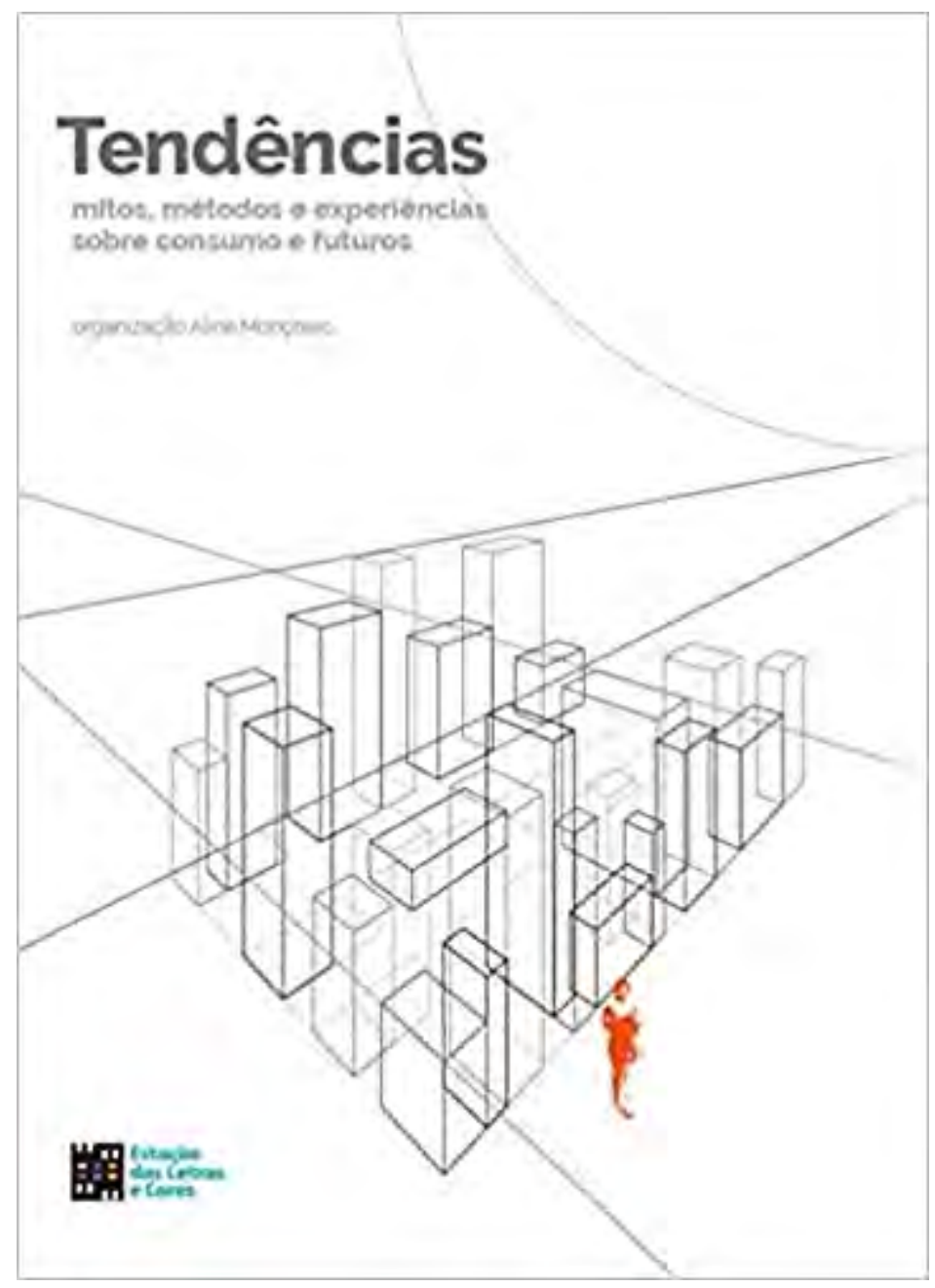

Fonte: Divulgação Editora Estação das Letras e Cores.

O termo tendência é amplamente utilizado dentro do universo relacionado ao vestuário e aos outros elementos da aparência, muitas vezes com visões um pouco generalizadas e até mesmo equivocadas sobre o conceito e as práticas de seus estudos. De toda maneira, saber qual será a próxima moda atrai interesse tanto das empresas produtoras quanto de

1 Doutora em Antropologia pelo PPGA-UFF. Professora do curso de Design de Moda na Universidade Veiga de Almeida. E-mail: marcia_mesq@yahoo.com.br. Lattes: http://lattes.cnpq.br/0813918182624845. 
seus consumidores desde as mudanças de hábitos de consumo ainda no século XIX, o surgimento dos primeiros chamados bureaux de style em meados do século XX, quando esse tipo de pesquisa foi institucionalizado, até os atuais reports constantes divulgados por agências de pesquisa com alcance global. Sua influência também vai além da moda e suas metodologias são utilizadas para apontar possibilidades futuras em outras áreas.

Além disso, as tendências, assim como as suas práticas de pesquisa e a divulgação das mesmas, são temas de investigação, reflexão e discussão acadêmica dentro dos campos do Design, da Moda e do Consumo. Assim nos apresenta o título Tendências: mitos, métodos e experiências sobre consumo e futuros, uma coletânea de artigos organizada por Aline Monçores e lançada pela Editora Estação das Letras e Cores em 2020.

O livro pretende aprofundar as discussões sobre o conceito de tendência como uma categoria por meio da qual podemos pensar a moda como um fenômeno social típico da modernidade e da contemporaneidade, assim como propor reflexões acerca das ações que envolvem suas identificações e os impactos dessas práticas para a produção e o consumo de objetos de moda. Ou seja, traz textos que abordam tanto os métodos e os usos do conceito de tendência aplicados ao mercado, como também artigos que discutem quais os sentidos e as implicações simbólicas do termo em reflexões mais históricas e sociológicas.

Sendo assim, trata-se de uma obra que transita bem entre o campo acadêmico e o mercado - se é que ainda é válido fazer tal distinção, abordando um tema pouco explorado como objeto de estudo no Brasil e profissionalmente dominado por empresas estrangeiras, como bem pontuam alguns de seus artigos.

Os trabalhos publicados são de autoras que pesquisam diferentes aspectos da temática das tendências e da projeção de cenários futuros, fazendo também essa circulação entre mercado e academia, com observações advindas de suas próprias experiências como pesquisadoras de tendências e investigações no âmbito acadêmico.

Como explica Monçores na introdução - ela também uma pesquisadora na prática e estudiosa do tema, que foi objeto de sua tese de doutorado (2012) -, o livro foi organizado em temáticas que compõem seu subtítulo, divisão que também será seguida nesta presente resenha. A primeira parte, Mitos, apresenta textos com abordagens históricas e que procuram desconstruir algumas visões pré-estabelecidas desse conceito. Em seguida, Métodos é composta por artigos que, como o nome já indica, tratam de formas de se conceituar o que seria uma tendência e como ela vai dialogar com o campo da moda, bem como trabalhos sobre como investigar comportamentos e projetar possíveis cenários. Por fim, em Experiências, são apresentadas percepções e discussões das autoras acerca da pesquisa de tendência como parte do mercado de moda, especialmente acerca do cenário atual para empresas e profissionais brasileiros.

\section{Desconstruindo as tendências no senso comum}

A primeira parte do livro abre com o artigo de Aline Monçores sobre como as grandes exposições do século XIX, que apresentavam ao público as mais variadas novidades e invenções do período, influenciaram o ciclo de lançamentos de constantes que definem o 
que é a moda. Tais feiras podem ser vistas como representações da expressão de alguns dos principais valores da modernidade, como a importância de tudo aquilo que é considerado novo, de um olhar idealizado e direcionado para o futuro. Além disso, esses eventos também contribuíram para reflexões acerca do que autores como Colin Campbell (2001) e Grant McCracken (2003) definem como o consumo moderno, ou seja, formas de consumir que surgem a partir de mudanças sociais advindas das revoluções ocorridas no período e dos novos valores da modernidade. Embora os objetos apresentados nas feiras, as chamadas "grandes invenções", não pudessem ser comprados pelo público no momento da visitação, a ida a um desses acontecimentos era uma forma de lazer e de busca por conhecimento, movida pela curiosidade que o novo despertava. A argumentação do texto relaciona esses fenômenos como uma das origens da preocupação por se saber quais serão os próximos modismos.

Em seu segundo artigo, Monçores busca fazer uma análise crítica de algumas visões teóricas bastante comuns na literatura de moda, especificamente de tendências, que costumam explicar o surgimento desses fenômenos em razão das disputas entre classes sociais. Embora não negue a importância das marcações de classe na construção do gosto e como elementos distintivos, como teorizou Bourdieu (2013), e, por conseguinte, influência naquilo que será considerado "vanguarda" ou "fora de moda", em seus termos, a autora argumenta que apenas esse viés não dá conta de explicar a complexidade da origem do conceito de tendência. A moda, assim como o anseio por saber o que estar por vir, também tem como origem as mudanças de valores surgidas na modernidade, como argumentam autores como Simmel (2014) e Lipovetsky (2009), já apresentadas no artigo anterior.

Já em Fads: as novelas e as febres de moda, a autora procurar demarcar as diferenças do que seriam os "fads", do título do artigo, do conceito de tendência. Ao contrário dessas últimas, que são indicações de modismos futuros, os "fads" ou as febres de consumo são fenômenos de moda rápidos e muito populares. É bastante comum, principalmente em alguns veículos da mídia - sejam os tradicionais impressos, sejam as novas mídias digitais -, o uso da palavra tendência e até mesmo trend para algo que está na moda naquele momento e não algo por vir, como Monçores já havia relatado em outro artigo seu (MONÇORES, 2013). Para exemplificar as diferenças, são utilizados casos de febres de consumo influenciadas por novelas brasileiras, especialmente o da personagem Solange, de Vale Tudo.

Essa primeira seção do livro é encerrada com artigo de Amanda Queiroz Campos que faz uma interessante relação entre a pesquisa de tendências e o conceito de "sistema de peritos" de Giddens (2002). O autor afirma que a modernidade teria como uma de suas principais dinâmicas a produção de desencaixes, de descontinuidades nas estruturas sociais. Tais dinâmicas provocariam uma percepção de risco constante, outra característica das sociedades modernas já amplamente discutida pela Sociologia. Os principais mecanismos de desencaixe, segundo Giddens, seriam os sistemas peritos, ou seja, sistemas abstratos de conhecimento técnico e profissional que estruturam nossa vida social. Por meio da construção de credibilidade pela especialização, esses sistemas procurariam firmar relações de confiabilidade para driblar justamente as incertezas que pairam em uma sociedade de risco. Campos mostra como antecipar novas modas seria uma forma de escapar de tais riscos: no caso, de criar uma coleção sem sucesso. Para isso, os bureaux de tendência precisam se constituir como "sistemas peritos", estabelecendo relações de confiança com as empresas do setor. 


\section{As muitas formas de se pesquisar tendências}

Os trabalhos da segunda parte do livro apresentam diversas maneiras de se pensar o que são tendências a partir das metodologias adotadas nas investigações, bem como os diferentes objetivos dessas maneiras de se pesquisar e prospectar futuros. 0 primeiro texto traz um paralelo que Aline Monçores faz entre a noção de dialética de Hegel e como identificar tendências. De acordo com o seu argumento, o seu surgimento pode ser identificado ao observarmos o embate entre uma força dominante, como uma estética vigente (tese), e um movimento que busca diferenciar-se dela (antítese). Para Hegel, a síntese não seria necessariamente o equilíbrio entre essas forças, mas o resultado dessa disputa. A síntese, por sua vez, tem o potencial de se tornar uma nova tese. Ao observar essas dinâmicas sociais, podemos apontar comportamentos que tendem a virar as novas modas vigentes ou, nos termos dialéticos, novas teses.

Solange Riva Mezabarba assina o segundo artigo da seção acerca da interlocução entre as pesquisas de tendências e a Antropologia. Comumente, o termo etnografia é acionado por pesquisadores como um dos muitos métodos qualitativos utilizados por eles, quase como um sinônimo das interações com pessoas por meio de entrevistas e visitas breves a certos locais. Até mesmo como uma prática de coolhunting. Além disso, existe ainda a expectativa de que a etnografia, por si só, já indique possíveis futuros. No entanto, a autora defende que é preciso compreender o termo de forma mais ampla e profunda, pois, para a Antropologia, etnografar vai além de conversas, necessitando imersão, observação consistente e a própria maneira de compreensão e escrita do que foi observado e de como foi o processo de "estar lá". Além de ser um retrato de um momento presente, que pode sim contribuir para a prospecção de tendências, sozinho não as desvenda.

0 terceiro texto traz descrições das diferentes formas de estudo das tendências por meio do trabalho de campo feito pela pesquisadora Sandra Regina Rech na plataforma Trends Observer, em Portugal. As descrições realizadas pela autora dos diversos métodos e tipos de coleta e análises de dados adotados pela empresa contribuem para uma sistematização mais elaborada de tais práticas e para definições mais exatas do que são cada um desses métodos. Apesar de serem categorias adotadas por uma empresa específica, o trabalho de Rech vai na contramão das generalizações e confusões nos usos e entendimentos de certos termos dessa área da pesquisa de tendências, apresentando um trabalho descritivo e imersivo das/nas características de cada metodologia observada.

No último texto da seção metodológica, Cidda Siqueira apresenta os estudos do futuro, que realizam prospecções de possíveis cenários a longo prazo. Por ser uma área que comumente é cercada de certa mística - alguns pesquisadores são vistos quase como gurus que misteriosamente captam acontecimentos futuros -, a autora se engaja em apresentar a origem desse tipo de estudo e seus principais métodos e conceitos. Como ela descreve, trata-se de uma prática já bastante utilizada em estratégia militar e nos campos do marketing e da economia, mas que também pode ser aplicada em trabalhos de menor escala, dialogando com os processos projetuais do design. Como Siqueira argumenta, esse tipo de pesquisa 
pode contribuir como uma fonte de informações estratégicas para se desenvolver novos produtos e se pensar em inovações que atendam com mais eficiência as futuras demandas dos consumidores.

\section{Vivenciando as tendências na prática}

A última seção traz dois artigos que refletem sobre o estudo de tendências como ocupação profissional e mercado, com suas empresas e circulação de informações. Aline Monçores e Ana Claudia Lopes fazem uma descrição da pesquisa de tendências como um campo profissional, apresentando as principais empresas que atualmente lideram esse setor. 0 texto analisa as terminologias adotadas para os diferentes perfis de profissionais e tarefas nesse tipo de estudo, como coolhunter, cuja expertise costuma ter sentidos múltiplos, especialmente no mercado brasileiro. As autoras também apresentam as estruturas e formas de trabalho dessas empresas, levando para o leitor informações de bastidores interessantes e informativas para quem se interessa em atuar na área.

O livro se encerra com o texto de Flávia Mendonça que mostra uma importante discussão acerca da centralização da produção de informações sobre tendências nas mãos de empresas europeias e americanas. Apesar de muitas delas terem informantes em países como o Brasil, que fazem relatórios com fenômenos interessantes e inovadores nesses locais, a análise e a divulgação desses dados ainda estão majoritariamente nas mãos dos países desenvolvidos. Essas informações voltam para as marcas nacionais pelas lentes dessas empresas, que muitas vezes se distanciam de aspectos culturais e sociais nossos. Com essa discussão, a autora aponta a importância para uma "descolonização" do olhar do estudo de tendências a fim de contribuir para uma criação de uma moda de fato mais conectada com as realidades locais. 


\section{Referências}

BOURDIEU, Pierre. A distinção: crítica social do julgamento. Porto Alegre: Zouk, 2013.

CAMPBELL, Colin. A ética romântica e o espírito do consumismo moderno. Rio de Janeiro: Rocco, 2001.

GIDDENS, Anthony. Modernidade e identidade. Rio de Janeiro: Jorge Zahar Editor, 2002.

LIPOVETSKY, Gilles. 0 império do efêmero: a moda e seu destino nas sociedades modernas. São Paulo: Companhia das Letras, 2009.

MCCRACKEN, Grant. Cultura \& consumo: novas abordagens ao caráter simbólico dos bens e das atividades de consumo. Rio de Janeiro: Mauad, 2003.

MONÇORES, Aline. Tendências, o novo constante: um estudo sobre a origem das tendências no campo da moda. Rio de Janeiro. 177 f. Tese (Doutorado) - Programa de Pós-Graduação em Design, Pontifícia Universidade Católica do Rio de Janeiro, Rio de Janeiro, 2012.

MONÇORES, Aline. Tendência de moda - Invenção da mídia? In: IX Colóquio de Moda, 2013, Fortaleza. Anais.... Fortaleza: Universidade Federal do Ceará, 2013.

SIMMEL, Georg. Da psicologia da moda: um estudo sociológico. In: SOUZA, Jessé; ÖELZE, Berthold (orgs.). Simmel e a modernidade. 2. ed. Brasília: Editora UNB, 2014. p. 159-168. 